\title{
Prevalence of malnutrition in patients at first medical oncology visit: the PreMiO study
}

\section{Maurizio Muscaritoli ${ }^{1}$, Simone Lucia ${ }^{1}$, Alessio Farcomeni ${ }^{2}$, Vito Lorusso ${ }^{3}$, Valeria Saracino ${ }^{3}$, Carlo Barone ${ }^{4}$, Francesca Plastino ${ }^{4}$, Stefania Gori ${ }^{5}$, Roberto Magarotto ${ }^{5}$, Giacomo Carteni ${ }^{6}$, Bruno Chiurazzi ${ }^{6}$, Ida Pavese ${ }^{7}$, Luca Marchetti ${ }^{7}$, Vittorina Zagonel $^{8}$, Eleonora Bergo $^{8}$, Giuseppe Tonini ${ }^{9}$, Marco Imperatori ${ }^{9}$, Carmelo Iacono ${ }^{10}$, Luigi Maiorana ${ }^{10}$, Carmine Pinto ${ }^{11}$, Daniela Rubino ${ }^{11}$, Luigi Cavanna ${ }^{12}$, Roberto Di Cicilia ${ }^{12}$, Teresa Gamucci ${ }^{13}$, Silvia Quadrini ${ }^{13}$, Salvatore Palazzo ${ }^{14}$, Stefano Minardi ${ }^{14}$, Marco Merlano ${ }^{15}$, Giuseppe Colucci ${ }^{16}$ and Paolo Marchetti ${ }^{17,18}$, on behalf of the PreMiO Study Group ${ }^{19}$}

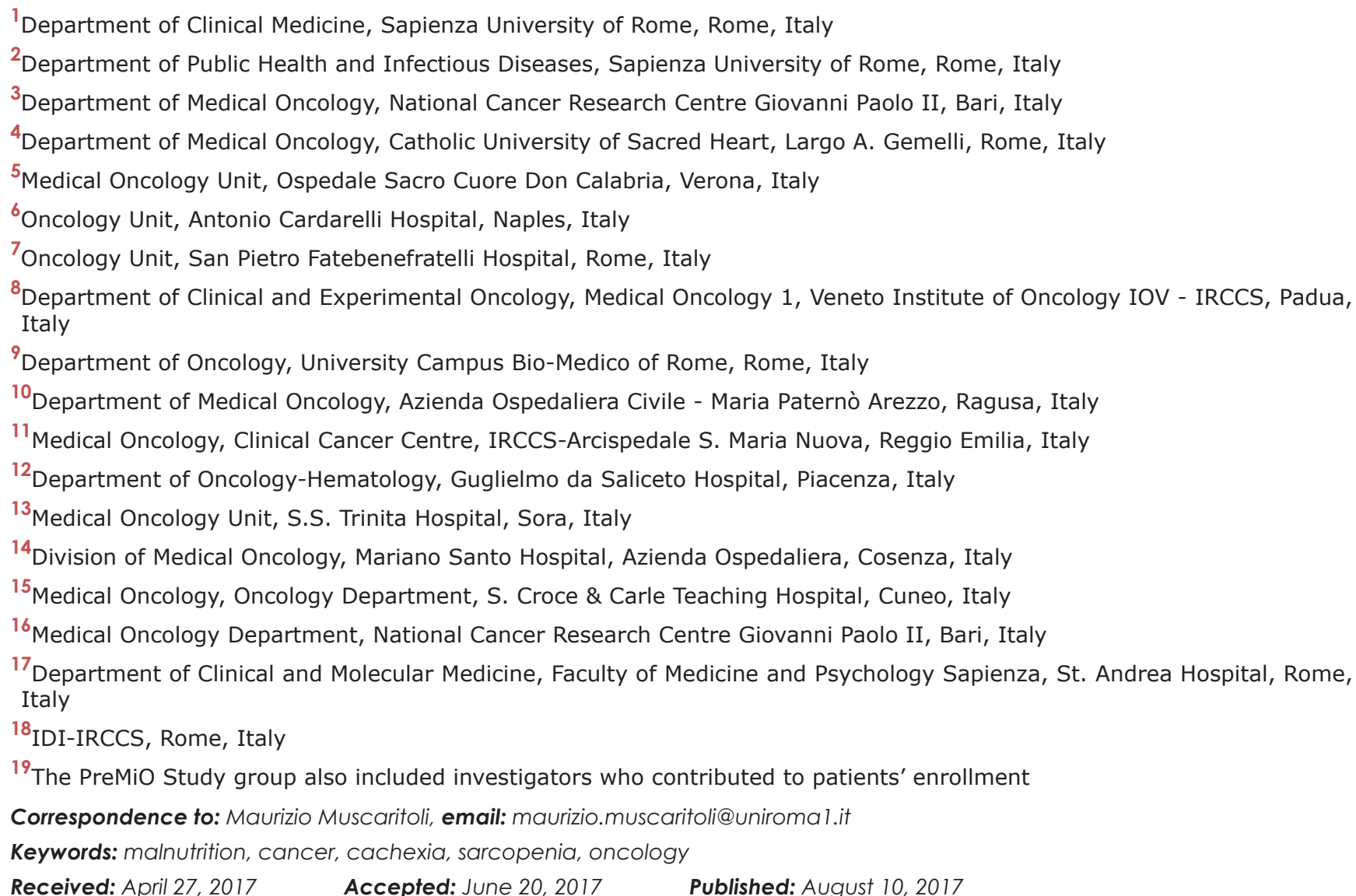
Copyright: Muscaritoli et al. This is an open-access article distributed under the terms of the Creative Commons Attribution License 3.0 (CC BY 3.0), which permits unrestricted use, distribution, and reproduction in any medium, provided the original author and source are credited.

\section{ABSTRACT}

Background: In cancer patients, malnutrition is associated with treatment toxicity, complications, reduced physical functioning, and decreased survival. The Prevalence of Malnutrition in Oncology (PreMiO) study identified malnutrition or its risk among cancer patients making their first medical oncology visit. Innovatively, oncologists, not nutritionists, evaluated the nutritional status of the patients in this study. 
Methods: PreMio was a prospective, observational study conducted at 22 medical oncology centers across Italy. For inclusion, adult patients ( $>18$ years) had a solid tumor diagnosis, were treatment-naive, and had a life expectancy $>3$ months. Malnutrition was identified by the Mini Nutritional Assessment (MNA), appetite status with a visual analog scale (VAS), and appetite loss with a modified version of Anorexia-Cachexia Subscale (AC/S-12) of the Functional Assessment of AnorexiaCachexia Therapy (FAACT).

Findings: Of patients enrolled $(N=1,952), 51 \%$ had nutritional impairment; $9 \%$ were overtly malnourished, and $43 \%$ were at risk for malnutrition. Severity of malnutrition was positively correlated with the stage of cancer. Over $40 \%$ of patients were experiencing anorexia, as reported in the VAS and FAACT questionnaire. During the prior six months, $64 \%$ of patients lost weight (1-10 kg).

Interpretation: Malnutrition, anorexia, and weight loss are common in cancer patients, even at their first visit to a medical oncology center.

\section{INTRODUCTION}

\section{Prevalence and consequences of malnutrition in cancer}

The high prevalence of cancer-related malnutrition and its negative consequences are taken too lightly in most oncology units. Studies from Germany [1], France [2-4], Spain [5], and Brazil [6] reported malnutrition prevalence ranging from $25 \%$ to over $70 \%$ based on nutritional assessments. Indeed, people with cancer are among the most malnourished of all patient groups [7]. Malnutrition in cancer patients seems to be particularly evident when a precise measurement of body composition is used for detection (e.g., computerized tomography); in such studies, $50 \%$ to $80 \%$ of patients had low lean body mass, a correlate of malnutrition [7]. Unfortunately, clinicians often miss malnutrition risk in cancer patients [2], as do many patients and their caregivers [8]. Even when malnutrition risk is recognized, it may not be adequately addressed. Hospital studies in Europe showed that only 1 in 3 cancer patients at risk of malnutrition in fact received nutritional support $[3,5]$.

When cancer-related malnutrition goes untreated, consequences can be serious. Malnourished colorectal cancer patients tolerated fewer cycles of chemotherapy [9], while other cancer patients with sarcopenia/ malnourishment were at high risk for toxicity of chemotherapy [10]. Further, malnourished patients undergoing treatment for oral cancers scored lower on quality of life (QOL) scales related to physical function, while those who were nourished and able to maintain or gain weight had significantly better QOL [11]. Malnutrition also increased financial costs for managing cancer patients, including costs for longer hospital stays and higher rates of complications following cancerrelated surgery $[4,5,12]$. At its most severe, patients who were malnourished had a 2- to 5-fold higher risk of dying compared to patients with little or no evidence of malnutrition, as seen in both short- and long-term followup studies $[1,4,9]$.

Due to generally low awareness of cancerassociated malnutrition, strategies for taking early actions to prevent and treat anorexia, cachexia, and sarcopenia are overlooked by many oncologists. The PreMiO study was conceived to quantify malnutrition and its signs among cancer patients making their first visit for medical oncology care in Italy. Our ultimate goal is to raise oncologists' awareness to the pressing need for early assessment of nutritional status in cancer patients and the need for providing appropriate nutritional care.

\section{Definition of malnutrition in cancer}

Malnutrition in cancer patients differs dramatically from malnutrition due to simple starvation [13]. The multiple causes and serious consequences of diseaseassociated malnutrition in cancer include anorexia, cachexia (ranging from pre-cachexia to cachexia), and sarcopenia (Figure 1) [14, 15]. Malnutrition in cancer is a result of inadequate nutritional intake that can lead to a depletion of body stores of fat and lean mass, and ultimately result in reduced physical function [16]. Initially, people with cancer may experience appetite loss resulting from altered appetite signals [17]. Cancer patients may also have physical restrictions that reduce food intake and nutrient absorption such as mouth ulcers, diarrhea, vomiting, pain, intestinal obstructions, or malabsorption $[18,19]$.

Systemic inflammation is often present in cancer, resulting from pro-inflammatory cytokines released from tumors or immune cells [7]. This inflammation may increase the body's metabolic needs, depress appetite, and initiate accelerated muscle protein catabolism. Cachexia, the resulting multifactor wasting syndrome, extends across a spectrum from pre-cachexia (identifiable by clinical symptoms and metabolic markers) to extensive weight loss in refractory cachexia $[7,10,14,15,20]$. 
When anorexia and cachexia/inflammation continue to progress, muscle mass can become depleted, causing the typical cachectic phenotype of the last stages of disease. The loss of lean body mass, and resulting loss of physical function, is known as sarcopenia. Muscle wasting and sarcopenia also occurs in overweight and obese patients, undermining their physical function while retaining an appearance of obesity. This makes sarcopenia particularly difficult to detect in the growing population of overweight and obese cancer patients $[7,10]$. Notably with cancer, the loss of skeletal muscle is a powerful negative prognostic factor for people of any body mass index (BMI) [21]. Skeletal muscle mass loss is associated with higher risk of toxicity from chemotherapy, reduced time to tumor progression, poor surgical outcome, physical function impairment, and increased mortality [21-25].

\section{RESULTS}

\section{Patient demographics and tumor characterization}

Between June 2012 and November 2014, a total of 1952 cancer patients (931 men and 1021 women) were enrolled into the study on their first visit to a medical oncology center. Those enrolled were well distributed among sites in the northern $(N=651)$, central $(N=596)$, and southern $(N=705)$ regions of Italy. Mean age (years) was $62.7 \pm 12.9$, mean BMI $\left(\mathrm{kg} / \mathrm{m}^{2}\right)$ was $24.8 \pm 4.4$, and mean weight $(\mathrm{kg})$ was $68.4 \pm 13.2$.

With primary tumor stratification by site, breast cancer was the most frequent, followed by genitourinary tract, colorectal, and lung cancers (Table 1).

By cancer stage, $24.5 \%$ of all tumors were localized (i.e., stage I and II), 18.7\% regionally spread (i.e., stage III), and $48.0 \%$ were metastatic (stage IV); tumor stage was not defined in 173 patients $(8.9 \%)$.

Tumor stages at first oncology visit varied considerably by primary tumor type (Table 1). For this reason, further data analyses were performed by stratifying patients into non-metastatic ( $\mathrm{M} 0, N=843$, cancer stages
I to III) and metastatic (M1, N=936, cancer stage IV) subgroups.

\section{Nutritional status: malnutrition, weight loss, appetite loss (anorexia)}

Based on MNA scoring, 51.1\% of patients (49.2\% of women and $52.9 \%$ of men) had nutritional impairment, including risk of malnutrition and overt malnutrition (Figure 2A). Malnutrition and its risk were significantly higher in M1 patients (Figure 2B), $(P<0.001)$. As determined by MNA, $40.1 \%$ of patients without metastases (M0) already had poor nutritional status at their first oncology visit. Of these, $36.5 \%$ were at risk of malnutrition, and $3.5 \%$ were malnourished. Malnutrition was evidenced in $13.6 \%(N=127)$ of M1 patients.

By site of primary tumor, patients with the highest frequency of malnutrition/undernutrition qualifying MNA score $(<17)$ were those with gastroesophageal, pancreatic, head and neck, and lung tumors (Figure 3); those with breast tumors were least likely to be malnourished. Prevalence of overt malnutrition was significantly higher in M1 compared to M0 patients $(P<0.001)$.

Unintentional weight loss is another marker of undernutrition or its risk. At the first medical oncology visit, $65 \%$ of patients $(N=1253)$ in the study population had experienced weight loss during the previous 6 months: $28.4 \%$ lost more than $10 \%$ of body weight, $36.2 \%$ lost $5 \%$ to $10 \%$, and $35.4 \%$ lost $<5 \%$. The actual weight loss ranged from 1 to $10 \mathrm{~kg}$. Prevalence of unintentional weight loss was greater in M1 patients (76.2\%) $(P<0.001$, IC $95 \% 18.4$ to 27.2 ). Notably, $53 \%$ of patients without metastases (M0) had already experienced weight loss at the first oncology visit.

\section{Appetite loss/anorexia}

Nearly all enrolled patients completed the FAACT questionnaire for anorexia $(N=1949)$ and the VAS selfscoring of appetite $(N=1857)$. Based on FAACT scores, poor appetite was present in $41 \%$ of patients $(N=802)$, with mean scores varying by tumor type and stage of disease

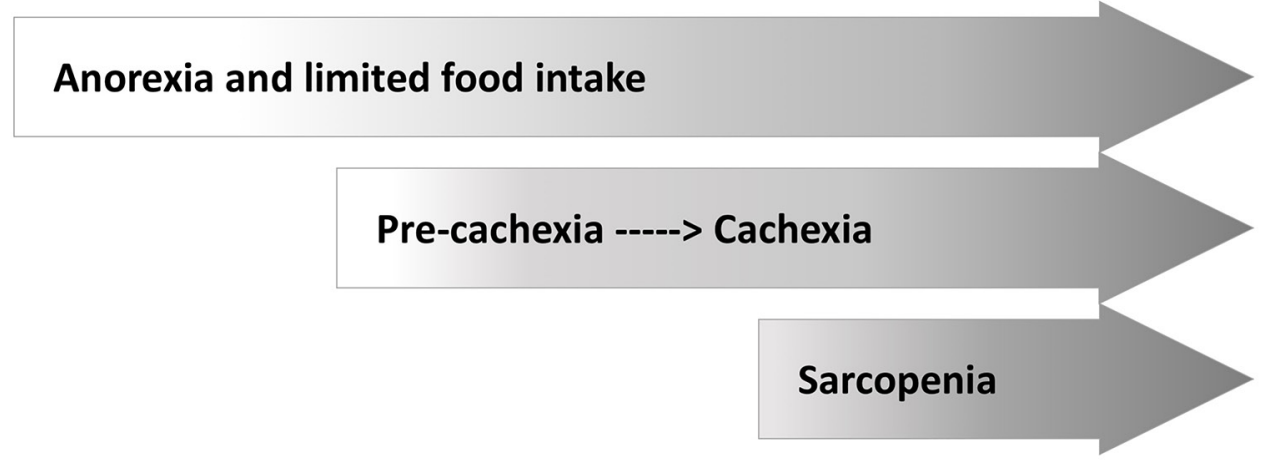

Figure 1: Causes and consequences of malnutrition in cancer: anorexia, cachexia, and sarcopenia. 
Table 1: Frequency of primary tumor types with distribution by tumor stage

\begin{tabular}{lccccc}
\hline Primary tumor type & $\begin{array}{c}\text { Frequency, \% of all } \\
\text { tumors }\end{array}$ & Stage I, \% & Stage II, \% & Stage III, \% & Stage IV, \% \\
\hline Breast & 22.1 & 27.5 & 29.2 & 16.0 & 18.5 \\
Genitourinary tract & 17.7 & 15.1 & 15.7 & 20.6 & 40.9 \\
Colorectal & 16.3 & 4.1 & 11.0 & 29.2 & 50.9 \\
Lung & 16.0 & 1.3 & 3.8 & 15.3 & 75.1 \\
Other cancer ${ }^{1}$ & 7.2 & 17.0 & 6.4 & 10.6 & 41.8 \\
Gastroesophageal & 6.5 & 7.1 & 4.8 & 15.9 & 64.3 \\
Pancreatic & 4.8 & 0.0 & 4.3 & 18.3 & 67.7 \\
Head and neck & 3.2 & 3.2 & 6.5 & 25.8 & 54.8 \\
Other GI & 3.1 & 3.3 & 1.6 & 19.7 & 62.3 \\
Liver/bile duct & 1.8 & 5.6 & 0.0 & 8.3 & 80.6 \\
Unknown primary & 1.3 & 0.0 & 0.0 & 4.0 & 56.0 \\
site & & & & & 48.0 \\
ALL CANCERS & 100 & 11.6 & 12.9 & 18.7 & \\
\hline
\end{tabular}

${ }^{1}$ Other cancer includes: sarcoma, mesothelioma, mesenchymal, skin, endocrine and hematologic tumors.

(Table 2). According to FAACT score, gastroesophageal and pancreatic cancer patients were already anorectic in the non-metastatic phase of the disease. By contrast, all metastatic patients were anorectic based on the FAACT questionnaire (Table 2). By VAS scoring, $44.5 \%$ of patients $(N=826)$ perceived appetite impairment (VAS score $\leq 70)$; the mean VAS score was $67.0 \pm 22.6$; scores varied by tumor type and disease stage (Table 2). Patients

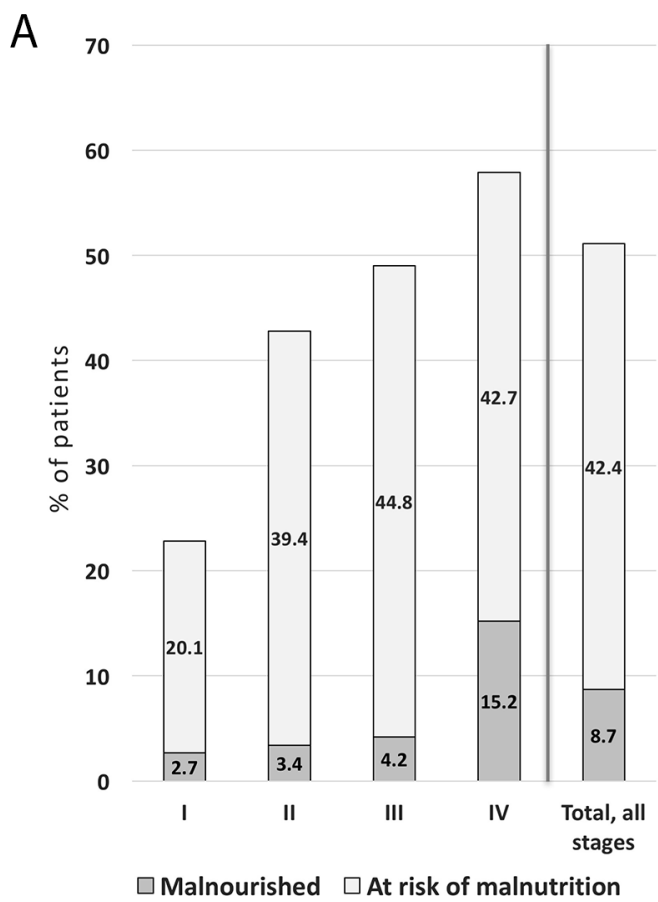

B 70

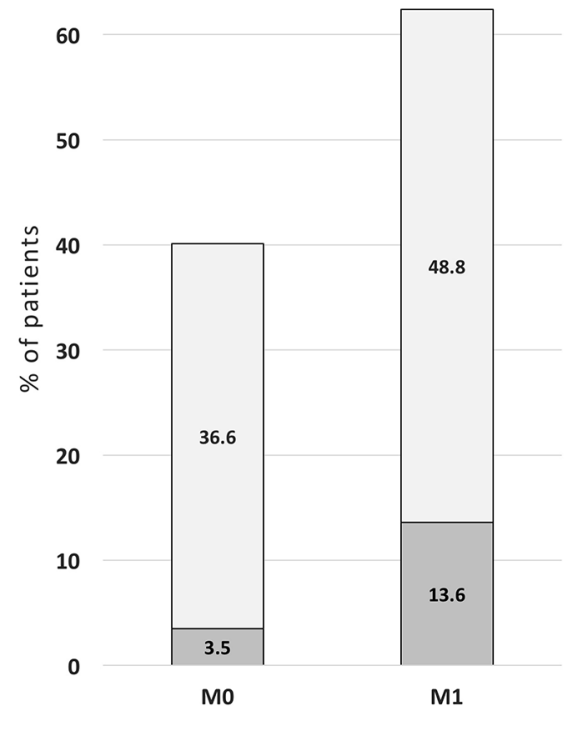

$\square$ At risk of malnutrition $\square$ Malnourished

Figure 2: PreMiO patients with malnutrition or malnutrition risk using MNA scoring with results shown by tumor stage and for all tumors (A) as well as classified in M0 and M1 groups (B) $(N=1925) . P<0.001$ among cancer stage groups. Malnutrition was defined as MNA score $<17$, while risk of malnutrition was represented by MNA scores of 17 to 23.5 . M0 = stage I-III, M1 = stage IV. 
with gastroesophageal, pancreatic and other GI cancer were already anorectic in the non-metastatic phase of the disease. All patients in M1 stage were anorectic based on the VAS (Table 2). Patients with appetite loss reported the main reasons for decreased food intake were early satiety $(69 \%)$, taste changes $(40.3 \%)$, nausea or vomiting $(31.9 \%)$, meat aversion $(28.9 \%)$ and smell disturbances (16.8\%).

Patients who assessed their disease as "severe and difficult to cure" had a lower appetite based on FAACT and VAS scores, and higher degree of malnutrition according to MNA $(P<0.001$; Supplementary Tables $1-3)$.

\section{Cachexia and pre-cachexia}

An unexpectedly high proportion of patients met the criteria for cachexia in both M0 and in M1 groups. More than $70 \%$ of pancreatic and gastroesophageal cancer patients, more than $60 \%$ of liver, colorectal, and GI tract, and more than $40 \%$ of lung, head and neck, and genitourinary cancer patients could be classified as cachectic, based on BMI and weight loss (Figure 4) using the criterion based on Fearon et al [14]. A notably high proportion of M0 patients exhibited cachexia, including those with breast cancer.

We also assessed for the presence of pre-cachexia in a subset of patients $(N=1085)$. Pre-cachexia criteria were cumulatively met by $16.1 \%$ of patients (range $3.4 \%$ to $28.8 \%$ at different primary tumor sites); the prevalence of pre-cachexia in M0 and M1 patients is shown (Figure 5). Cumulatively, the highest prevalence of pre-cachexia was observed in the "other cancers" group. This group includes neoplasms known to have only limited impact on nutritional status, i.e., sarcomas, mesotheliomas, mesenchymal, skin, endocrine and hematologic tumors. As expected, the prevalence of malnutrition and cachexia in this group of patients was relatively low (Figures 4 and 5 , respectively).

\section{Inflammation as revealed by elevated CRP}

Serum C-reactive protein (CRP) determinations were available only in a subset of patients $(N=1087)$. Cumulatively, more than $50 \%$ of these patients with all tumor types, except breast cancer, had CRP levels greater than the upper normal limit (Figure 6). With the exception of unknown primary tumors, the prevalence of elevated CRP was higher in M1 with respect to M0 patients $(P<0.001)$. Further, CRP levels correlated positively with cancer stages $(\mathrm{r}=0.256, P<0.001)$, the presence of cachexia ( $\mathrm{r}=0.189, P<0.001)$, and weight loss ( $\mathrm{r}=0.232$, $P<0.001$ ), and correlated negatively with anorexia-related scores ( $\mathrm{r}=-0.216, P<0.001$ for VAS score, $\mathrm{r}=-0.251$, $P<0.001$ for FAACT score) and malnutrition-related scores $(\mathrm{r}=-0.262, P<0.001$ for MNA score).

\section{DISCUSSION}

At Italian cancer care centers, oncology physicians enrolled patients in the PreMiO study and assessed nutritional status on their first visit for care. The oncologists reviewed recent weight changes, assessed

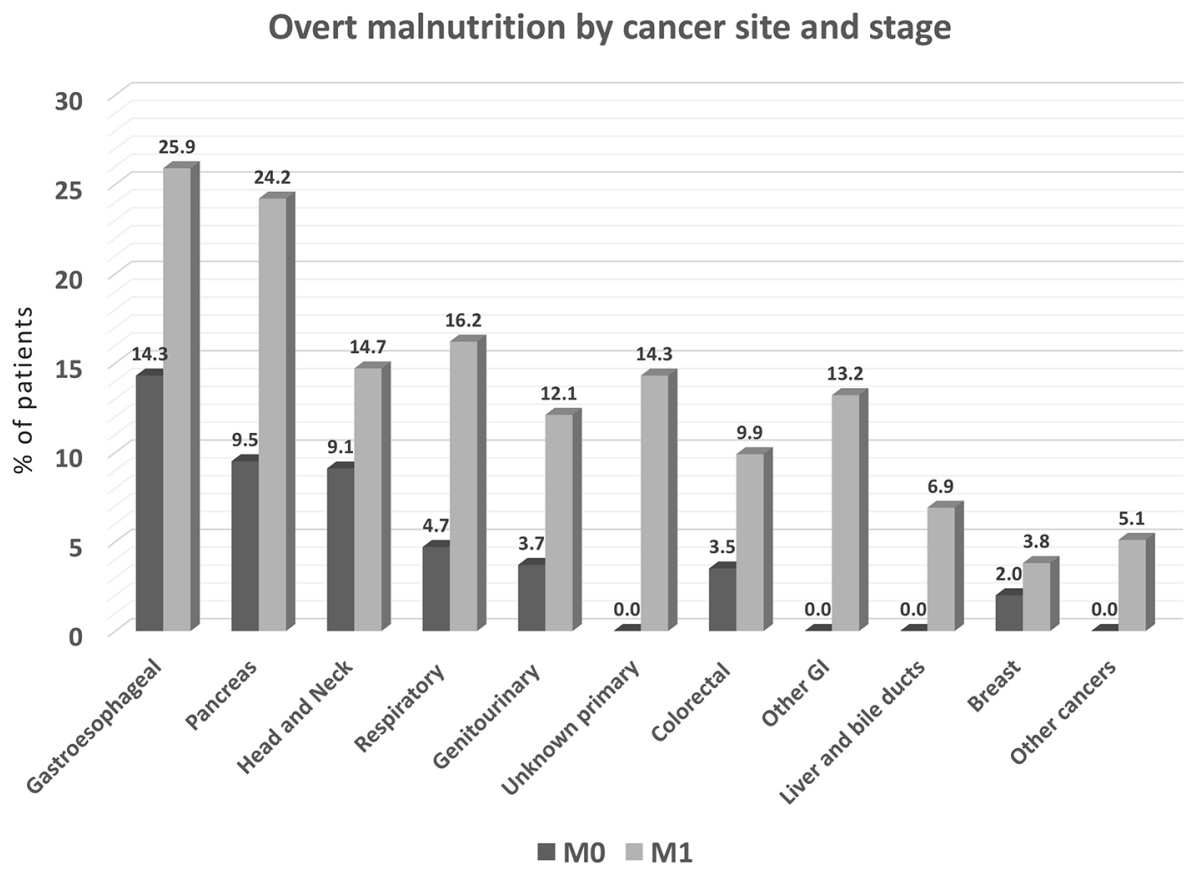

Figure 3: Prevalence of overt malnutrition by cancer site (\% of patients with specified tumor type), with malnutrition defined as MNA score $<\mathbf{1 7}(\mathbf{N = 1 9 2 5})$. M0 = stage I-III, M1 = stage IV. $P<0.001$ among cancer site groups. 
Table 2: Patient appetite scores by cancer site, based on FAACT $(N=1949)$ and VAS $\operatorname{scores}(N=1857)$

\begin{tabular}{|c|c|c|c|c|c|c|}
\hline Cancer site & $\begin{array}{c}\text { FAACT } \\
\text { M0 }\end{array}$ & $\begin{array}{c}\text { FAACT } \\
\text { M1 }\end{array}$ & $\begin{array}{c}\text { FAACT } \\
\text { Total }\end{array}$ & $\begin{array}{c}\text { VAS appetite } \\
\text { M0 }\end{array}$ & $\begin{array}{c}\text { VAS appetite } \\
\text { M1 }\end{array}$ & $\begin{array}{c}\text { VAS appetite } \\
\text { total }\end{array}$ \\
\hline Breast & $33 \pm 5$ & $29 \pm 5$ & $32 \pm 5$ & $73 \pm 20$ & $69 \pm 19$ & $73 \pm 20$ \\
\hline Genitourinary tract & $32 \pm 5$ & $28 \pm 6$ & $30 \pm 6$ & $72 \pm 18$ & $61 \pm 22$ & $67 \pm 21$ \\
\hline Colorectal & $32 \pm 5$ & $29 \pm 5$ & $30 \pm 5$ & $72 \pm 23$ & $65 \pm 22$ & $68 \pm 22$ \\
\hline Lung & $31 \pm 5$ & $29 \pm 5$ & $29 \pm 6$ & $71 \pm 24$ & $64 \pm 23$ & $66 \pm 23$ \\
\hline Other cancer ${ }^{1}$ & $33 \pm 6$ & $29 \pm 6$ & $32 \pm 6$ & $78 \pm 22$ & $69 \pm 21$ & $75 \pm 22$ \\
\hline Gastroesophageal & $27 \pm 6$ & $23 \pm 6$ & $25 \pm 6$ & $58 \pm 23$ & $52 \pm 21$ & $54 \pm 21$ \\
\hline Pancreatic & $28 \pm 4$ & $24 \pm 7$ & $25 \pm 6$ & $62 \pm 22$ & $48 \pm 27$ & $53 \pm 26$ \\
\hline Other GI & $34 \pm 5$ & $28 \pm 6$ & $30 \pm 5$ & $69 \pm 18$ & $62 \pm 21$ & $63 \pm 21$ \\
\hline Liver/bile duct & $33 \pm 2$ & $26 \pm 5$ & $28 \pm 5$ & $82 \pm 8$ & $62 \pm 21$ & $65 \pm 20$ \\
\hline Head and neck & $33 \pm 6$ & $30 \pm 5$ & $31 \pm 5$ & $75 \pm 23$ & $64 \pm 19$ & $68 \pm 22$ \\
\hline Unknown primary site ${ }^{2}$ & 26 & $25 \pm 6$ & $28 \pm 6$ & 20 & $45 \pm 17$ & $55 \pm 24$ \\
\hline ALL CANCERS & $32 \pm 5$ & $28 \pm 6$ & $30 \pm 6$ & $72 \pm 21$ & $62 \pm 23$ & $67 \pm 23$ \\
\hline
\end{tabular}

Cutoff points for poor appetite are FAACT $\leq 30$ and VAS appetite score VAS $\leq 70$. M0 = stage I-III, M1 = stage IV. Data are expressed as Mean \pm SD

'Other cancer includes: sarcoma, mesothelioma, mesenchymal, skin, endocrine and hematologic tumors.

${ }^{2} \mathrm{~N}=1$ if SD not indicated.

FAACT, Functional Assessment of Anorexia-Cachexia Therapy (questionnaire); VAS, visual analog scale of appetite $\mathrm{SD}$, standard deviation.

appetite, looked for evidence of inflammation, and employed validated scoring methods and criteria to detect malnutrition, anorexia, and cachexia. Findings showed that first-visit PreMiO patients were often malnourished or at risk for malnutrition when they entered the study, i.e., $40 \%$ to $80 \%$ of patients had signs and indicators of nutritional impairment even in early disease stages, particularly in gastroesophageal, pancreatic, head and neck, and colorectal cancer patients. Importantly, our study demonstrated that oncologists can be effectively trained to perform assessments that identify malnutrition and its risks.

Malnutrition is prevalent with cancer, and both percent weight loss and BMI predict survival independently of conventional prognostic factors [26]. Accordingly, newly published expert guidelines advise nutrition screening and assessment for all cancer patients [18]. In the presence of a tumor, the body mounts an intense inflammatory response [27] associated with anorexia and cachexia, which can lead to progressive loss of skeletal muscle mass (with or without loss of fat mass) and worsen impairment of function [27]. The pathophysiology of cancer cachexia is characterized by negative protein and energy balance, which is driven by a variable combination of reduced food intake and abnormal metabolism [14]. Elevated blood CRP, a biochemical marker of inflammation, can be used to help detect cancerrelated nutrition problems that predispose to poor outcomes
[27]. Systemic inflammation was highly prevalent in PreMiO patients with non-metastatic disease, as well as for those with metastatic disease; based on CRP measures for $56 \%$ of study patients, inflammation by cancer site ranged from $21 \%$ to $100 \%$ of M0 patients and $55 \%$ to $91 \%$ in M1 patients (Figure 6).

There is no simple biomarker for malnutrition nor is there expert agreement on which screening/ assessment tools are most accurate [28]. The MNA has been used successfully for lung cancer patients [29, 30], demonstrating a better predictive and prognostic value compared with measuring weight loss alone in the baseline nutritional evaluation of patients [30]. Because overweight and obesity are widespread today, malnutrition may be overlooked when conventional anthropometric measures such as height, weight, and body mass index are used exclusively for risk assessment [7]. It is therefore important to use screening tools and assessment methods that take other factors into account, e.g., recent weight loss, loss of appetite, loss of lean body mass, and impairment of physical abilities [29, 31, 32]. Specialized screening methods (bioimpedance analysis), and precise tools for assessment of lean body mass (computed tomography) are newly recognized as favorable ways to identify cancerrelated malnutrition or its risk $[7,10,32]$.

In this study, the prevalence of overt malnutrition (determined by MNA [33]) was considerably lower than 
the prevalence of cachexia (using Fearon's criteria;[14] see Figures 3 and 4). This disparity is attributable largely to the different diagnostic criteria used to determine malnutrition and cachexia. Recently published guidelines from the European Society for Enteral and Parenteral Nutrition (ESPEN) [13], classify cachexia of chronic diseases — including cancer — as a form of "disease-related malnutrition (DRM) with inflammation," and propose that DRM with inflammation and cachexia are interchangeable terms. Nonetheless, while the concepts are aligned, the diagnostic criteria are different. This creates confusion that leads to delays in identifying and treating cancer-related malnutrition and cachexia in everyday clinical practice. We join with others to urgently call for scientific societies to align the definitions and diagnostic criteria of DRM with inflammation and cachexia [28].

Oncologists often question whether preventing or treating cancer-related malnutrition will affect their patients' prognosis. Recent evidence helps resolve the uncertainty, as available data suggest there are benefits of nutritional intervention to improve outcomes in cancer patients. For example, the high prevalence of malnutrition at diagnosis of gastric cancer was associated with high rates of surgical site infections following surgical tumor removal; the rate of surgical site infection was significantly reduced when patients were given well-managed pre-operative nutrition support [34]. Even for cancer patients who are not malnourished before surgery, 14-day pre-surgical nutrition therapy significantly improved nutritional status and reduced post-operative surgical complications compared to cancer patients who did not receive pre-surgical nutrition support [35]. When lung cancer patients were given high-energy oral nutritional supplements containing eicosapentaenoic acid (a fatty acid with inflammationblunting properties), food intake and body composition improved, fatigue decreased, and appetite improved, as did measures of physical function and quality of life [36, 37].

Nutritional status affects acceptability and tolerability of anticancer therapies, in turn altering therapeutic choices. An accurate evaluation of nutritional status is of paramount importance in treating cancer patients, especially in early stages [32]. The efficacy of chemotherapy, for example, could be impaired by a reduction in the patient's therapy tolerance, which is influenced by a poor nutritional status [7, 38].

Lastly, in cancer patients, the relationship between disease curability/severity and subjective symptoms, such as appetite loss or degree of malnutrition, underlines the need for an integrated support team including a psychooncologist, who can address and treat psychological aspects (depression, loss of hope, and anxiety) while other team members deal with medical issues.

Altogether, results of the PreMiO study support a call-to-action for oncologists to (1) be aware of malnutrition risk in their patients, even in those with nonmetastatic disease, (2) conduct early nutrition screening and make ongoing assessments of nutritional status of cancer patients, and (3) commit to early, aggressive treatment of malnutrition as part of routine supportive cancer treatments. We hope that as nutritional assessment

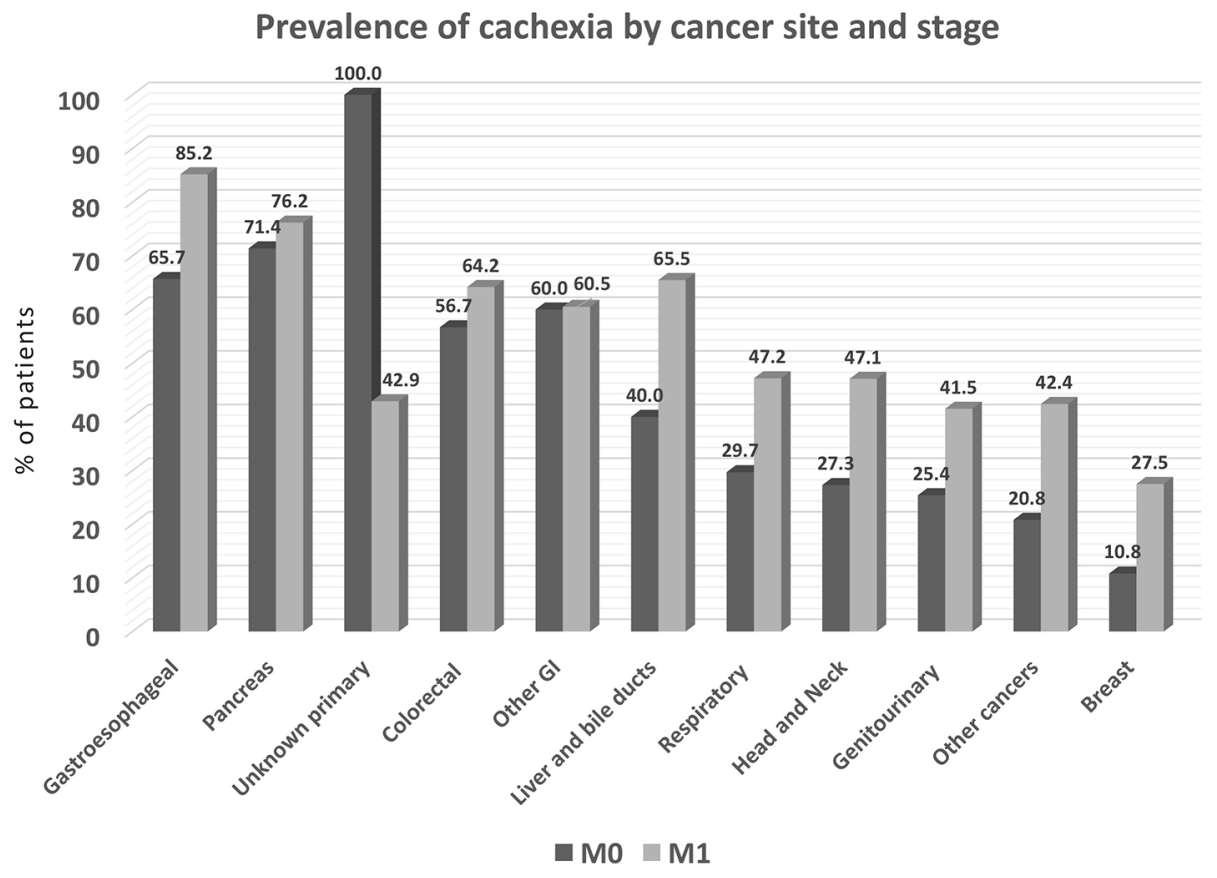

Figure 4: Prevalence of cachexia by primary tumor type in the study population $(\boldsymbol{N}=1952)$. Cachexia is defined by weight loss $>5 \%$ or by the dual criteria of BMI $<20$ with weight loss of $2 \%$ to $5 \%$. M0 = stage I-III, M1 $=$ stage IV. $P<0.001$ among cancer site groups. 


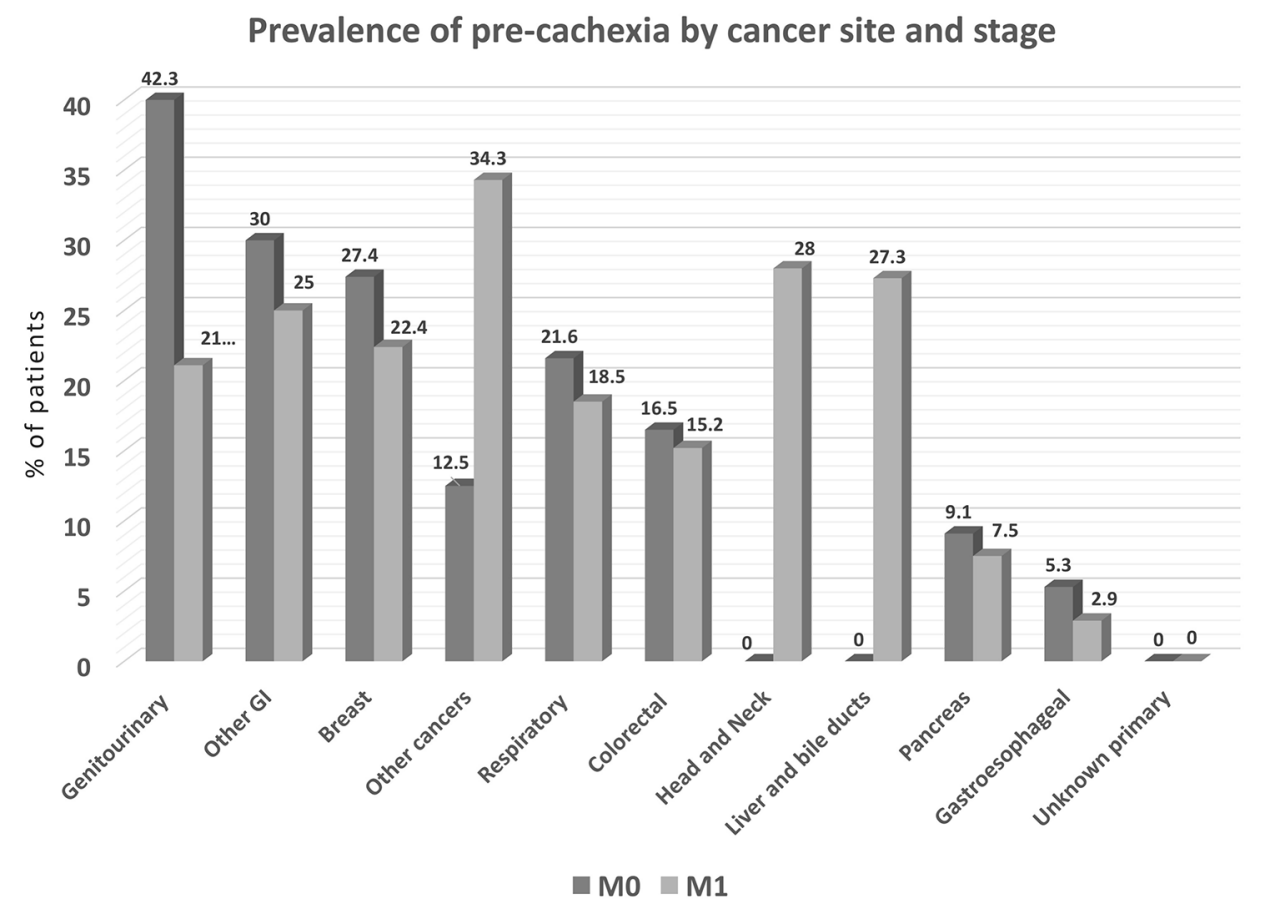

Figure 5: Prevalence of pre-cachexia by cancer site, as determined by percent of patients with unintentional weight loss up to 5\% during prior 6 months, along with chronic systemic inflammation and anorexia-related symptoms $(\boldsymbol{N}=\mathbf{1 0 8 5})$. M0 = stage I-III, M1 = stage IV. $P<0.05$ among cancer site groups.

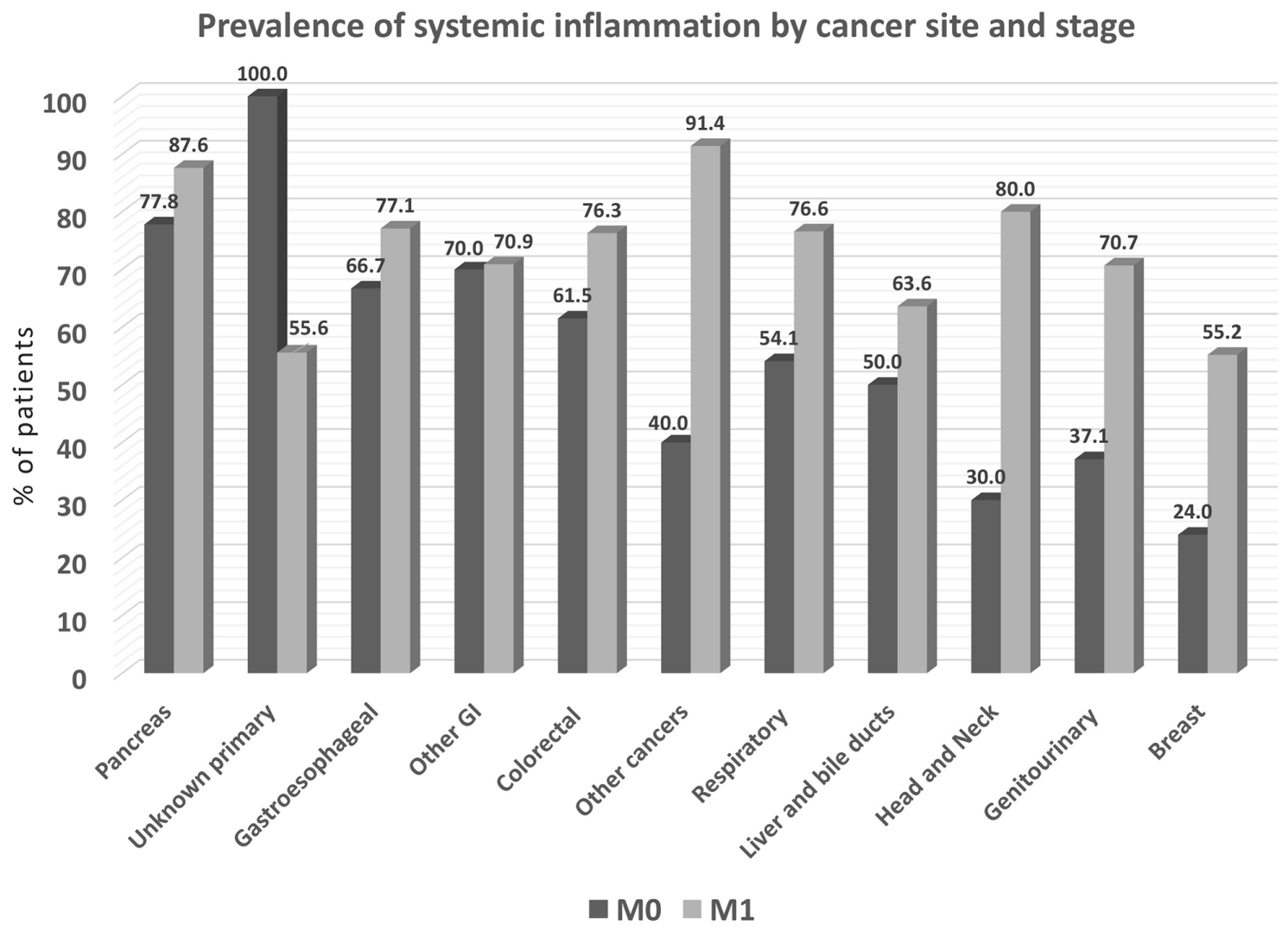

Figure 6: Prevalence of systemic inflammation by cancer site, as determined by \% patients with elevated blood levels of C-reactive protein $(\boldsymbol{N}=\mathbf{1 0 8 7}) . \mathrm{M} 0=$ stage I-III, M1 = stage IV. $P<0.001$ among cancer site groups. 
Table 3: Malnutrition terms and measurements tools

\begin{tabular}{|c|c|c|c|}
\hline & $\begin{array}{l}\text { Anorexia and limited food } \\
\text { intake }\end{array}$ & $\begin{array}{l}\text { Pre-cachexia and } \\
\text { cachexia }\end{array}$ & Sarcopenia \\
\hline Description & $\begin{array}{l}\text { Food intake falls as a result } \\
\text { of: } \\
\text { - Altered appetite signals } \\
\text { from tumor or its treatment } \\
\text { - Physical issues that limit } \\
\text { food intake }\end{array}$ & $\begin{array}{l}\text { Weight loss worsens as: } \\
\text { - Inflammatory cytokines } \\
\text { drive catabolism, } \\
\text { increasing metabolic } \\
\text { needs } \\
\text { - Nutrient intake continues } \\
\text { to fall }\end{array}$ & $\begin{array}{l}\text { Cachexia and anorexia can } \\
\text { lead to sarcopenia: } \\
\text { - Body fat reserves may } \\
\text { become depleted } \\
\text { - Lean body mass is lost } \\
\text { - Physical function declines }\end{array}$ \\
\hline \multicolumn{4}{|c|}{ Nutrition tools used in PreMIO study: } \\
\hline - Malnutrition screening & \multicolumn{3}{|c|}{ Mini Nutritional Assessment (MNA) } \\
\hline \multirow[t]{3}{*}{ - Nutrition assessment } & $\begin{array}{l}\text { VAS - patient-reported } \\
\text { intake }\end{array}$ & $\begin{array}{l}\text { CRP above upper limit of } \\
\text { normal }\end{array}$ & \\
\hline & $\begin{array}{l}\text { FAACT - patient perception c } \\
\text { anorexia/cachexia }\end{array}$ & f signs, symptoms of & \\
\hline & & \multicolumn{2}{|c|}{$\begin{array}{l}\text { Weight loss }>5 \% \text { during prior } 6 \text { months } \\
\text { (or }>2 \% \text { for patients with low BMI or sarcopenia) }\end{array}$} \\
\hline
\end{tabular}

FAACT, Functional Assessment of Anorexia-Cachexia Therapy (questionnaire); VAS, visual analog scale of appetite; (questionnaire); CRP, C-reactive protein; BMI, body mass index.

and therapy become routine, survival and quality of life will improve for cancer patients [39].

\section{MATERIALS AND METHODS}

\section{Study design}

PreMIO was a prospective, observational, multicenter study to assess nutritional status and related factors in cancer patients (ClinicalTrials.gov: NCT01622036). The study was conceived, promoted and carried out jointly by the Italian Society of Artificial Nutrition and Metabolism (SINPE) and the Italian Association of Medical Oncology (AIOM); the protocol was published online at https:/clinicaltrials.gov/ct2/show/ NCT01622036? term $=$ premio\&rank $=1$.

Enrollment was conducted at ESMO (European Society for Medical Oncology)-designated Centers of integrated Oncology and Palliative Care and other medical oncological centers $(N=22)$ in Italy.

Inclusion criteria were: patients at first medical oncology visit; diagnosis of solid tumor; age $>18$ years; no previous anticancer therapies (e.g. radiotherapy or chemotherapy); life expectancy $>3$ months according to a palliative prognostic score; [40] and informed consent. Cancer type and stage of disease were determined by the oncologist.

Exclusion criteria were inability to feed orally or intestinal obstruction; decompensated metabolic disorders; severe liver failure (total bilirubin $>1.5 \mathrm{mg} / \mathrm{dL}(25 \mu \mathrm{mol} / \mathrm{L})$, and aspartate aminotransferase (AST or SGOT) to alanine aminotransferase (ALT or SGPT) ratio >2-times the Upper
Limit Normal (ULN) or, in the case of metastatic liver cancer, >5-times ULN; severe kidney failure indicated by creatinine $>2.0 \mathrm{mg} / \mathrm{dL}(177 \mu \mathrm{mol} / \mathrm{L})$ or creatinine clearance $(\mathrm{ClCr})<50 \mathrm{~mL} / \mathrm{min}$; acute decompensated heart failure; active infection; primary brain tumor or metastatic brain tumors; severe psychiatric disorders; Mini-Mental State Examination (MMSE) score $<25 / 30$ (in patients aged >70); [41] and inadequate logistical support for participation. These criteria eliminated the sickest patients and those least able to consume adequate nutrition, thus creating a higher bar for demonstrating malnutrition prevalence in the remaining study subjects.

\section{Variables}

PreMiO quantified the occurrences of malnutrition and its risk, anorexia and appetite loss, weight loss, and pre-cachexia/cachexia at the first medical oncology visit (Table 3). Patient-perceived disease severity and treatability were also assessed. All evaluations were performed by an oncologist or Senior Resident in Oncology. Prior to the start of the study, these physicians were identified and trained to use the study's nutrition assessment tools.

\section{Malnutrition-related score}

Malnutrition (as undernutrition) and risk of malnutrition were identified using the Mini Nutritional Assessment (MNA) tool; malnourished individuals had MNA scores $<17$, those at risk of malnutrition had scores of 17 to 23.5, and well-nourished patients $>23.5$ [29, 30]. 
The MNA has been found to correlate with laboratory parameters used to identify inflammation associated with cachexia, and was independently associated with survival in a study of metastatic lung cancer patients (median age 66 years) [29].

\section{Anorexia-related score}

Appetite loss (anorexia) is commonly evaluated in cancer patients with a two-step questionnaire, first to determine the presence of appetite loss, and next to quantify it. For the first step, this study used a modified version of Anorexia-Cachexia Subscale (AC/S-12) of the Functional Assessment of Anorexia-Cachexia Therapy (FAACT) questionnaire [17, 42]. Next, appetite loss was quantified on a visual analog scale (VAS) of appetite [17]. The FAACT score quantified patient perception of symptoms and signs that correlated with anorexia, and the VAS appetite score represented the patient's perception of his or her appetite. Patients self-reported oral food intake on a VAS scale of 0 (no food intake) to 100 (normal food intake). The PreMiO study used cutoff points of FAACT score $\leq 30$ for anorexia and VAS $\leq 70$ for appetite loss representative of anorexia [17]. These cutoff values were recently established in a study of patients with advanced cancer evaluated prior to chemotherapy [17].

\section{Weight loss}

Weight loss was determined as the difference between the patient's usual weight ( 6 months ago, as recalled by patient) and his or her weight at study entry. In a recent study, weight loss in cancer patients independently predicted survival, and a gradient of decreasing survival was observed as the percentage of weight loss increased and BMI decreased [26].

\section{Pre-cachexia and cachexia determination}

Pre-cachexia is a disease-associated condition characterized by unintentional weight loss up to $5 \%$ during prior 6 months, along with chronic systemic inflammation and anorexia-related symptoms (as determined by VAS and FAACT results defined above). Inflammation was identified as CRP level above the ULN for the assay used; anorexia-related symptoms (as determined by VAS and FAACT results defined above). Cachexia was identified based on criteria defined by Fearon et al:[14] diseaseassociated weight loss $>5 \%$ during the prior 6 months or by the combination of progressive weight loss (more than $2 \%$ ) and $\mathrm{BMI}<20 \mathrm{~kg} / \mathrm{m}^{2}$.

\section{Disease severity and curability}

The patient-perceived severity and curability of the disease was measured to assess the relationship between patient-perceived degree of severity/curability and psychological well-being, quality of life, or other subjective evaluations. Participants rated severity and curability of their disease on two ten-point scales ranging from 1 (not severe or difficult to cure) to 10 (highly severe or easy to cure). The perception of control and curability has an effect on depression and anxiety [43], which may, in turn, influence nutritional status.

\section{Data collection}

Patient information was recorded on a data collection sheet at the time of enrollment and then uploaded to a dedicated website platform. Patient anonymity was maintained by assigning each patient a study identification number. The data generated at each participating center were compiled at the Coordination Center of the Istituto Dermopatico dell'Immacolata, officially designated by the Ministry of Health as a Centre for Treatment and Research (IRCCS). Patients were stratified by cancer type/site and disease stage, and by age, sex, and general health condition.

\section{Statistical analyses}

All statistical analyses were performed using IBM SPSS Statistics version 20.0 (SPSS Inc., Chicago, IL, USA). Continuous variables were expressed as mean value \pm standard deviation (SD). Analysis of variance (ANOVA) was used for analysis of patients' perceptions of their appetite and the severity and the treatability of their condition. The chi-squared test was used to evaluate the prevalence of unintentional weight loss in different groups. The Spearman correlation test was used to determine the strength of correlations between cancer site, inflammation, and perception of anorexia [44].

\section{Ethical considerations}

Data were collected under the auspices of research ethics approvals for human experimentation at all contributing institutions and at the IDI-IRCCS.

\section{Abbreviations}

AC/S-12: Anorexia-Cachexia Subscale

BMI: Body mass index

CRP: C-reactive protein

FAACT: Functional Assessment of AnorexiaCachexia Therapy

M0: Localized cancer, stages I-III

M1: Metastatic cancer, stage IV

MNA: Mini Nutritional Assessment

VAS: Visual analog scale of appetite

ULN: Upper Limit Normal

\section{Author contributions}

Drs M Muscaritoli and P Marchetti designed the study; Drs M Muscaritoli, S Lucia, A Farcomeni, and P Marchetti analyzed the data; Drs M Muscaritoli, S Lucia, and P Marchetti wrote the manuscript; all other authors 
conducted the study; all authors reviewed and commented on the manuscript.

\section{ACKNOWLEDGMENTS}

The study was made possible thanks to the coordination and generous support by A.I.O.M. Fondazione, Italy.

The authors thank Cecilia Hofmann, PhD, Western Springs, Illinois, USA, for her helpful editorial assistance in preparation of this manuscript.

\section{CONFLICTS OF INTEREST}

None of the authors declares any conflict of interest which might have interfered with conducting the present study and with the interpretation of the results.

\section{FUNDING}

The study was supported by an unrestricted educational grant by Fresenius-Kabi Italy. Fresenius Kabi Italy did not interfere in the planning and elaboration of the study protocol, in data collection, evaluation and interpretation, and in the preparation of the manuscript. (No grant number)

\section{PreMiO study group}

L. Fioretto, G. Cipriani - Oncology Department, Azienda Sanitaria di Firenze, Florence, Italy

S. Barni, V. Lonati - ASST Bergamo Ovest, Medical Oncology Unit, Treviglio (BG), Italy

A. Frassoldati, G.C. Surace - Division of Oncology, S. Anna Hospital, Ferrara, Italy

G. Porzio, F. Martella - Medical Oncology Unit, S. Salvatore Hospital - University of L'Aquila, L'Aquila, Italy

G. Altavilla, M. C. Santarpia - Medical Oncology Unit, Department of Human Pathology, University of Messina, Messina, Italy

P. Pronzato, A. Levaggi - Department of Medical Oncology, U.O. Oncologia Medica 2, IRCCS AOU San Martino - IST, Genova, Italy

A. Contu, M. Contu - Medical Oncology Unit, Ss. Annunziata Hospital, Sassari, Italy

V. Adamo, R. Berenato - Medical Oncology Unit A.O. Papardo \& Department of Human Pathology University of Messina, Italy

F. Marchetti - Medical Oncology Unit, Ospedale Sacro Cuore don Calabria, Negrar, Verona, Italy

A. Pellegrino - Oncology Unit, San Pietro Fatebenefratelli Hospital, Rome, Italy
S. Violante - Medical Oncology, Oncology Department, S. Croce \& Carle Teaching Hospital, Cuneo, Italy

M. Guida - Medical Oncology Department, National Cancer Research Centre Giovanni Paolo II, Bari, Italy

\section{REFERENCES}

1. Maasberg S, Knappe-Drzikova B, Vonderbeck D, Jann H, Weylandt KH, Grieser C, Pascher A, Schefold JC, Pavel M, Wiedenmann B, Sturm A, Pape UF. Malnutrition predicts clinical outcome in patients with neuroendocrine neoplasias. Neuroendocrinology. 2017; 104:11-25.

2. Attar A, Malka D, Sabate JM, Bonnetain F, Lecomte T, Aparicio T, Locher C, Laharie D, Ezenfis J, Taieb J. Malnutrition is high and underestimated during chemotherapy in gastrointestinal cancer: an AGEO prospective cross-sectional multicenter study. Nutr Cancer. 2012; 64:535-542.

3. Hebuterne X, Lemarie E, Michallet M, de Montreuil CB, Schneider SM, Goldwasser F. Prevalence of malnutrition and current use of nutrition support in patients with cancer. JPEN J Parenter Enteral Nutr. 2014; 38:196-204.

4. Pressoir M, Desne S, Berchery D, Rossignol G, Poiree B, Meslier M, Traversier S, Vittot M, Simon M, Gekiere JP, Meuric J, Serot F, Falewee MN, et al. Prevalence, risk factors and clinical implications of malnutrition in French Comprehensive Cancer Centres. Br J Cancer. 2010; 102:966-971.

5. Planas M, Alvarez-Hernandez J, Leon-Sanz M, CelayaPerez S, Araujo K, Garcia de Lorenzo A; PREDyCES ${ }^{\circledR}$ researchers. Prevalence of hospital malnutrition in cancer patients: a sub-analysis of the PREDyCES ${ }^{\circ}$ study. Support Care Cancer. 2016; 24:429-435.

6. Silva FR, de Oliveira MG, Souza AS, Figueroa JN, Santos CS. Factors associated with malnutrition in hospitalized cancer patients: a cross-sectional study. Nutr J. 2015; 14:123.

7. Ryan AM, Power DG, Daly L, Cushen SJ, Ni Bhuachalla E, Prado CM. Cancer-associated malnutrition, cachexia and sarcopenia: the skeleton in the hospital closet 40 years later. Proc Nutr Soc. 2016; 75:1-13.

8. Gyan E, Raynard B, Durand JP, Lacau Saint Guily J, Gouy S, Movschin ML, Khemissa F, Flori N, Oziel-Taieb S, Bannier Braticevic C, Zeanandin G, Hebert C, Savinelli F, et al; NutriCancer2012 Investigator Group. Malnutrition in patients with cancer. JPEN J Parenter Enteral Nutr. 2017.

9. Aaldriks AA, van der Geest LG, Giltay EJ, le Cessie S, Portielje JE, Tanis BC, Nortier JW, Maartense E. Frailty and malnutrition predictive of mortality risk in older patients with advanced colorectal cancer receiving chemotherapy. J Geriatr Oncol. 2013; 4:218-226. 
10. Prado CM, Cushen SJ, Orsso CE, Ryan AM. Sarcopenia and cachexia in the era of obesity: clinical and nutritional impact. Proc Nutr Soc. 2016; 75:1-11.

11. Gellrich NC, Handschel J, Holtmann H, Kruskemper G. Oral cancer malnutrition impacts weight and quality of life. Nutrients. 2015; 7:2145-2160.

12. Melchior JC, Preaud E, Carles J, Brami M, Duru G, Fontaine E, Hebuterne X, Lukacs B, Zazzo JF, Panis Y, Nitenberg G. Clinical and economic impact of malnutrition per se on the postoperative course of colorectal cancer patients. Clin Nutr. 2012; 31:896-902.

13. Cederholm T, Barazzoni R, Austin P, Ballmer P, Biolo G, Bischoff SC, Compher C, Correia I, Higashiguchi T, Holst M, Jensen GL, Malone A, Muscaritoli M, et al. ESPEN guidelines on definitions and terminology of clinical nutrition. Clin Nutr. 2017; 36:49-64.

14. Fearon K, Strasser F, Anker SD, Bosaeus I, Bruera E, Fainsinger RL, Jatoi A, Loprinzi C, MacDonald N, Mantovani G, Davis M, Muscaritoli M, Ottery F, et al. Definition and classification of cancer cachexia: an international consensus. Lancet Oncol. 2011; 12:489-495.

15. Muscaritoli M, Anker SD, Argiles J, Aversa Z, Bauer JM, Biolo G, Boirie Y, Bosaeus I, Cederholm T, Costelli P, Fearon KC, Laviano A, Maggio M, et al. Consensus definition of sarcopenia, cachexia and pre-cachexia: joint document elaborated by Special Interest Groups (SIG) "cachexia-anorexia in chronic wasting diseases" and "nutrition in geriatrics". Clin Nutr. 2010; 29:154-159.

16. Lochs H, Allison SP, Meier R, Pirlich M, Kondrup J, Schneider S, van den Berghe G, Pichard C. Introductory to the ESPEN guidelines on enteral nutrition: terminology, definitions and general topics. Clin Nutr. 2006; 25:180-186.

17. Blauwhoff-Buskermolen S, Ruijgrok C, Ostelo RW, de Vet HC, Verheul HM, de van der Schueren MA, Langius JA. The assessment of anorexia in patients with cancer: cutoff values for the FAACT-A/CS and the VAS for appetite. Support Care Cancer. 2016; 24:661-666.

18. Arends J, Bachmann P, Baracos V, Barthelemy N, Bertz $\mathrm{H}$, Bozzetti F, Fearon K, Hutterer E, Isenring E, Kaasa S, Krznaric Z, Laird B, Larsson M, et al. ESPEN guidelines on nutrition in cancer patients. Clin Nutr. 2017; 36:11-48.

19. Farhangfar A, Makarewicz M, Ghosh S, Jha N, Scrimger R, Gramlich L, Baracos V. Nutrition impact symptoms in a population cohort of head and neck cancer patients: multivariate regression analysis of symptoms on oral intake, weight loss and survival. Oral Oncol. 2014; 50:877-883.

20. Dev R, Hui D, Chisholm G, Delgado-Guay M, Dalal S, Del Fabbro E, Bruera E. Hypermetabolism and symptom burden in advanced cancer patients evaluated in a cachexia clinic. $\mathrm{J}$ Cachexia Sarcopenia Muscle. 2015; 6:95-98.

21. Martin L, Birdsell L, Macdonald N, Reiman T, Clandinin MT, McCargar LJ, Murphy R, Ghosh S, Sawyer MB, Baracos VE. Cancer cachexia in the age of obesity: skeletal muscle depletion is a powerful prognostic factor, independent of body mass index. J Clin Oncol. 2013; 31:1539-1547.

22. Lieffers JR, Bathe OF, Fassbender K, Winget M, Baracos VE. Sarcopenia is associated with postoperative infection and delayed recovery from colorectal cancer resection surgery. Br J Cancer. 2012; 107:931-936.

23. Prado CM, Lieffers JR, McCargar LJ, Reiman T, Sawyer MB, Martin L, Baracos VE. Prevalence and clinical implications of sarcopenic obesity in patients with solid tumours of the respiratory and gastrointestinal tracts: a population-based study. Lancet Oncol. 2008; 9:629-635.

24. Prado CM, Baracos VE, McCargar LJ, Reiman T, Mourtzakis M, Tonkin K, Mackey JR, Koski S, Pituskin E, Sawyer MB. Sarcopenia as a determinant of chemotherapy toxicity and time to tumor progression in metastatic breast cancer patients receiving capecitabine treatment. Clin Cancer Res. 2009; 15:2920-2926.

25. Tan BH, Birdsell LA, Martin L, Baracos VE, Fearon KC. Sarcopenia in an overweight or obese patient is an adverse prognostic factor in pancreatic cancer. Clin Cancer Res. 2009; 15:6973-6979.

26. Martin L, Senesse P, Gioulbasanis I, Antoun S, Bozzetti F, Deans C, Strasser F, Thoresen L, Jagoe RT, Chasen M, Lundholm K, Bosaeus I, Fearon KH, Baracos VE. Diagnostic criteria for the classification of cancer-associated weight loss. J Clin Oncol. 2015; 33:90-99.

27. Laviano A, Koverech A, Mari A. Cachexia: clinical features when inflammation drives malnutrition. Proc Nutr Soc. 2015; 74:348-354.

28. Argiles J, Muscaritoli M. Unifying diagnostic criteria for cachexia: an urgent need. Clin Nutr. 2017; 36:910-911.

29. Gioulbasanis I, Georgoulias P, Vlachostergios PJ, Baracos V, Ghosh S, Giannousi Z, Papandreou CN, Mavroudis D, Georgoulias V. Mini Nutritional Assessment (MNA) and biochemical markers of cachexia in metastatic lung cancer patients: interrelations and associations with prognosis. Lung Cancer. 2011; 74:516-520.

30. Gioulbasanis I, Baracos VE, Giannousi Z, Xyrafas A, Martin L, Georgoulias V, Mavroudis D. Baseline nutritional evaluation in metastatic lung cancer patients: Mini Nutritional Assessment versus weight loss history. Ann Oncol. 2011; 22:835-841.

31. Isenring E, Elia M. Which screening method is appropriate for older cancer patients at risk for malnutrition? Nutrition. 2015; 31:594-597.

32. Muscaritoli M, Molfino A, Lucia S, Rossi Fanelli F. Cachexia: a preventable comorbidity of cancer. A T.A.R.G.E.T. approach. Crit Rev Oncol Hematol. 2015; 94:251-259.

33. Guigoz Y, Lauque S, Vellas BJ. Identifying the elderly at risk for malnutrition. The Mini Nutritional Assessment. Clin Geriatr Med. 2002; 18:737-757.

34. Fukuda Y, Yamamoto K, Hirao M, Nishikawa K, Maeda S, Haraguchi N, Miyake M, Hama N, Miyamoto A, Ikeda 
M, Nakamori S, Sekimoto M, Fujitani K, Tsujinaka T. Prevalence of malnutrition among gastric cancer patients undergoing gastrectomy and optimal preoperative nutritional support for preventing surgical site infections. Ann Surg Oncol. 2015; 22:778-785.

35. Kabata P, Jastrzebski T, Kakol M, Krol K, Bobowicz M, Kosowska A, Jaskiewicz J. Preoperative nutritional support in cancer patients with no clinical signs of malnutrition-prospective randomized controlled trial. Support Care Cancer. 2015; 23:365-370.

36. Sanchez-Lara K, Turcott JG, Juarez-Hernandez E, NunezValencia C, Villanueva G, Guevara P, De la Torre-Vallejo M, Mohar A, Arrieta O. Effects of an oral nutritional supplement containing eicosapentaenoic acid on nutritional and clinical outcomes in patients with advanced nonsmall cell lung cancer: randomised trial. Clin Nutr. 2014; 33:1017-1023.

37. van der Meij BS, Langius JA, Spreeuwenberg MD, Slootmaker SM, Paul MA, Smit EF, van Leeuwen PA. Oral nutritional supplements containing n-3 polyunsaturated fatty acids affect quality of life and functional status in lung cancer patients during multimodality treatment: an RCT. Eur J Clin Nutr. 2012; 66:399-404.

38. Gangadharan A, Choi SE, Hassan A, Ayoub NM, Durante G, Balwani S, Kim YH, Pecora A, Goy A, Suh KS. Protein calorie malnutrition, nutritional intervention and personalized cancer care. Oncotarget. 2017; 8:24009-24030. https://doi.org/10.18632/oncotarget.15103.

39. Muscaritoli M, Molfino A, Gioia G, Laviano A, Rossi Fanelli F. The "parallel pathway": a novel nutritional and metabolic approach to cancer patients. Intern Emerg Med. 2011; 6:105-112.

40. Maltoni M, Nanni O, Pirovano M, Scarpi E, Indelli M, Martini C, Monti M, Arnoldi E, Piva L, Ravaioli A, Cruciani G, Labianca R, Amadori D. Successful validation of the palliative prognostic score in terminally ill cancer patients. Italian Multicenter Study Group on Palliative Care. J Pain Symptom Manage. 1999; 17:240-247.

41. Folstein MF, Folstein SE, McHugh PR. "Mini-mental state". A practical method for grading the cognitive state of patients for the clinician. J Psychiatr Res. 1975; 12:189-198.

42. Ribaudo JM, Cella D, Hahn EA, Lloyd SR, Tchekmedyian NS, Von Roenn J, Leslie WT. Re-validation and shortening of the Functional Assessment of Anorexia/Cachexia Therapy (FAACT) questionnaire. Qual Life Res. 2000; 9:1137-1146.

43. Mazzotti E, Sebastiani C, Marchetti P. Patient perception of disease control and psychological distress. Cancer Manag Res. 2012; 4:335-340.

44. Artusi R, Verderio P, Marubini E. Bravais-Pearson and Spearman correlation coefficients: meaning, test of hypothesis and confidence interval. Int J Biol Markers. 2002; 17:148-151. 